\title{
How English Language Learning Textbooks Develop Learners' Communication Skills, Creative Language Production, Critical Thinking and Collaborative Learning
}

\author{
Dr. Muayyad Naji Ahmed \\ Ministry of Education / Open Educational College - Department of English \\ Baghdad - Iraq
}

\begin{abstract}
:
The aim of this research is to explain how English language learning textbook can develop the language learners' communication skills, creative language production, critical thinking and collaborative learning. Each skill is first explained in terms of definition and the targeted educational output sought. Then, the approaches to syllabus design that focus on developing these four skills are reviewed. Within each section of this research, the researcher sheds light on the teaching techniques involved. The researcher hopes to provide answers to the following questions:

- What is the theoretical / psychological foundation of each skill?

- What are the targeted educational outputs behind developing each skill?

- How can these four skills be integrated in English textbooks?

- What are the best classroom drills and teaching techniques required?

- How can the assessment procedures help measure the learners' progress in these skills?

The findings of this research may be useful to those who are in charge of editing English textbooks and to the teachers of English as well.
\end{abstract}

\section{Introduction:}

Language learners need to listen, speak, read and write with a reasonable level of accuracy and fluency in order to communicate effectively in different contexts. They also need to know the social and academic language skills necessary to persuade and inform others and to share different viewpoints. To be creative thinkers and produce creative language expressions, they need to develop an ability to personalize new knowledge and adapt it to create something that is uniquely their own. They need to know how to connect what they learn with what they already know, to think deeply about issues and to think critically about knowledge and information. To work collaboratively together, they need to get the necessary social language skills in order to contact or work with people of different cultures. They need to learn how to share ideas so that they can achieve the needed results.

Each of the above mentioned skills has a theoretical framework and practical procedures explaining how to deal with and develop them when designing
English language learning textbooks or to help choosing the suitable course. It is worth referring

here to Razmloo (2007: 127) who says that the large quantity of published materials now available in the market makes the selection of the right textbooks a challenging task.

\section{The Scope of the Research}

The next four chapters constitute the scope of this research on how to develop each skill and end up with conclusions.

\section{The Significance of the Research}

Teachers of English should be aware of the methodological strengths and weaknesses of instructional materials. They also should realize to what extent they can rely on textbooks in their daily teaching practice. Likewise, they will learn the key specifications that will enable them to make wise decisions when it comes to selecting, evaluating, and implementing English textbooks at the institutions where they work. 


\section{Section One}

\section{How English Language Textbooks Develop Learners' Communicative Skills}

Most modern English language textbooks use communicative texts as educational materials that focus on the genuine use of the language for communicative purposes in a variety of meaningful contexts. These texts, with the study of linguistic forms, offer opportunities for learners to communicate, interact and negotiate meaning. If we wish to ensure that our learners acquire the ability to communicate in an appropriate and efficient way, we have to consider the following components of the syllabus that are identified by Yalden (1982: 86-7):

- The purposes for which the learners wish to acquire the target language,

- The setting in which they will want to use the target language,

- The communicative events in which the learners will participate (everyday situations, vocational or professional situations, academic situations, and so on),

- The language functions and notions involved,

- The skills involved,

- The grammatical and lexical content that will be needed.

Another criterion for evaluating the language textbooks, as proposed by Richards (2005: 15), is that textbooks design should be based on three types of language practices; mechanical, meaningful and communicative. All these practices advocate communicative language learning in the language learning context. It is worth elaborating on Richards's three practices as follows.

\subsection{The Mechanical Practice}

The mechanical practice refers to controlled activities that involve repetition and substitution drills. They are designed to practice the use of particular grammatical items. In many textbooks, this practice demands sentence completion (usually with grammar activities in isolation), but it lacks authentic language negotiation. The following drill is an example of a mechanical practice. The learners are asked to compose sentences in isolation without a relevant context.

Complete the prompts in bold, using the present perfect $\mathrm{a}$. Choose a sports star.

and

just or never, as in the examples.

Examples:

- I can't sleep in here. I / not sleep / tent.

- I've never slept in a tent before.

- They are very happy. They / have / baby.
- They've just had a baby.

1. Who is that woman? I / not see her/ before.

2. This is my new dress. I/ buy it.

3. I'm not hungry. I / have / lunch.

4. Mom is angry with John. He / break / window.

\subsection{The Meaningful Practice}

The meaningful practice refers to those activities in which language is still controlled and the learners are required to make meaningful choices when carrying out practice. Below is an example of a meaningful practice. The learners have to answer several questions about someone's personal information. It is a meaningful activity in a context, yet, the context is quite limited.

Listen to the audio tape and find the following information.

a. What is the girl's name?

b. What does she want to be?

c. Where does she live?

d. What is unusual about her day?

\subsection{The Communicative Practice}

The communicative practice embodies those activities in which language is not totally predictable. Language production at this level is more spontaneous and authentic because meaning negotiation takes place within a real communicative context and real information is exchanged. The following drill is an example of a communicative practice. It provides a meaningful context because learners are asked to choose their favourite sports star. Although it suggests that learners make wh questions, the language is not totally predictable because it allows learners to make their own decisions. Also, language production is more spontaneous and authentic since learners are required to interview a classmate and engage in a process of meaning negotiation in a real communicative context where real information is shared. After the interview, learners are asked to write a report.

\section{An Interview:}

b. Make six questions to ask the sports star. (Use: how, what, when, where, do, why.)

c. Do your interview with a partner.

Follow up: Write your interview with the sports star. These three types of language practices essentially define the kinds of activities often featured in 
communicative textbooks. They are all expected to be included in the methodological sequence of the various units that constitute English textbooks, mainly because learners need to go through a process of controlled practice, by first working on easy-guided mechanical activities before eventually reaching a degree of free language practice that embraces the communicative interaction. Therefore, if textbooks are designed to develop language competence, one can assume that they should contain a well-balanced number of activities pertaining to the three types of language practices described above. Teachers of English also need to be aware of the frequency of these types of practices in English textbooks in order to be sure that the classroom material they use is effective for communicative purposes.

The researcher finds it worthy referring here to the concept of 'communicative competence' and how it can be activated. When we adopt Hymes' definition (1972: 271); communicative competence is the ability to convey and interpret messages and to negotiate meaning with other speakers in specific contexts, the major concern for developing learners' communicative competence should center primarily on the negotiation of meaning in real situational contexts. In this respect, there are four categories that define the notion of communicative competence. The first two categories refer to the use of the linguistic system: grammatical competence and discourse competence. The former refers to 'learner's knowledge of the grammar, vocabulary, phonology and semantics of a language" (Richards and Schmidt, 2002: 90) and allows speakers to know and understand the appropriate use of language forms. Without the knowledge of the linguistic code, communication would be absolutely impossible. The latter is every speaker's ability to connect sentences in a meaningful and coherent discourse when he "knows how to begin and end conversation" (ibid: 91).

The third category is the socio-linguistic competence, which involves knowledge of the sociocultural rules of language and the discourse in which language is used. It embodies the learner's ability to "use and respond appropriately to requests, apologies, thanks, invitations and so forth." (ibid: 90)

The fourth category is the strategic competence, which refers to the verbal and nonverbal communication strategies speakers use to compensate for breakdowns in communication due to insufficient levels of competence. In other words, speakers are able to use strategies to compensate for an imperfect knowledge of rules and a lack of vocabulary in the communicative process. Paraphrasing, repeating, and guessing are examples of strategic verbal competence. Gestures, mimicking, and body positions are examples of strategic nonverbal competence. All these strategies are valid when learners intend to negotiate meaning. Byram (1997: 8), however, explains that Hymes emphasizes the awareness of the relationship between linguistic and socio-cultural competence. Children, as Hymes (1972: 279) explains, "develop a general theory of speaking appropriately in their community, which they employ, like other forms of tacit cultural knowledge in conducting and interpreting social life". Byram (1997: 22) then remarks that foreign language teaching should concern itself not only with the practical questions of linguistic competence for communication, but also with the relationship between the language and the cultural practices and beliefs of a particular group. Accordingly, it is essential to recognize that competence in a foreign language also implies the acquisition and recognition of cultural practices. Therefore, the most complete term that Byram proposes is intercultural communicative competence.

Savignon (2001: 8) then contributes to the definition of communicative competence by stressing that communicative competence is relative and depends mainly on the cooperation of all participants, because it is a very dynamic conception in which at least two individuals are involved in the process of negotiating meaning. This idea suggests that language competence is the ability that allows learners to establish successful communication in a foreign language, in genuine contexts, and through everyday tasks found in real life. Being competent implies more than knowing the linguistic code; it also necessitates being able to negotiate meaning and to interact socially in the target language.

The foregoing perspectives lead us to consider the following:

- The contents of a language course should be based on social communicative functions and not merely on linguistic structures.

- The learners need to work in groups in order to establish meaningful negotiation when they are involved in role-playing activities, problemsolving tasks, dramatizations, and simulations of situations in real life. 
- The classroom materials and activities are to be authentic, as they reflect typical real-life situations.

Therefore, one would expect communicative textbooks to be designed in such a format that they can provide the means to enhance communicative competence.

Razmloo (2007:134) reports that Jack Richards was asked to list which principles he took into account when designing English language communicative textbooks. Richards replied by saying that textbooks need to make communication the focus of language learning. In his opinion, textbooks must create opportunities for interaction and the negotiation of meaning through the use of information sharing, problem solving, and role-play activities. The textbooks should link the different skills of listening, speaking, reading and writing, and ought to link the learning of grammar to communicative tasks.

In addition to the communicative role that Richards assigns to textbook activities, other authors also believe that authenticity is a major feature. Kramsch (2001:177) explains that the term "authentic" has been used as a reaction against the prefabricated artificial language of textbooks and the dialogues implemented in language classrooms. Authenticity refers to the way language is used in communication to fulfill a social purpose in a particular context. "It is the degree to which language teaching materials have the qualities of natural speech and writing taken from real-world sources such as newspapers, magazines, advertisements, travel brochures, etc." (Richards and Schmidt, 2002:42). To conclude, textbooks should introduce the language in a way which makes it "a vehicle for classroom communication, not just the object of study." (Larsen-Freeman, 2000: 125)

\section{Section Two}

\section{How to Promote Creativity in English Language Textbooks}

This section introduces a set of activities that can be introduced in English learning textbooks in order to improve students' creative language production.

When we consider creativity as a process of bringing something new, we highlight the fact that when learners are in a classroom, they become aware of their previous knowledge and use it with their new knowledge. Naiman (1998: 93) also states that "creativity is the process of turning imaginative ideas into reality." For him, creativity involves two processes: thinking, then producing; and he adds that innovation is the production or implementation of an idea.

The importance of creativity in English language learning textbooks can be explained in terms of the following points:

1. The learners' capability of producing sentences and even long texts (that they have never heard or seen before) is developed when they transform thoughts into language. By giving learners creative exercises, we help them think creatively.

2. The learners can use compensation strategies for making up for lack of language in a communicative situation such as miming, drawing, paraphrasing and imaginative ways of expression. The learners need such methods until they master the language.

3. Creative tasks in the language textbooks can lead to genuine communication and co-operation. They prepare learners for using the language instrumentally outside the classroom.

4. Creative tasks enrich classroom work and they make it more varied and more enjoyable by tapping into individual talents, ideas and thoughts.

Csikszentmihalyi (2013:79) elaborates that the following set of strategies spark a spirit of creativity in the foreign language field:

- Preparation: arousing curiosity of a problematic situation.

- Incubation: ideas fly below the threshold of consciousness.

- Insight: the moment when the puzzle starts to fall together.

- Evaluation: deciding if the insight is valuable and worth pursuing.

- Elaboration: translating the insight into its final work.

These strategies lead to create what is called personalized courses as students' performances are thoroughly analyzed and assessed according to their needs. Thus, the first consideration here is that the activities should be based on the participants' needs so that they could be more engaged in the classes.

Some of the features of productive language learning tasks that promote creative responses are identified by (Richards, 2013:12):

A.The challenging tasks, in which learners solve problems, discover something, overcome obstacles, or find information. 
B. The interesting topics that learners already find interesting and that they would want to read about outside of class, such as stories we find about sports and entertainment personalities we find on YouTube and the internet.

C.The personal element: activities that make connections to the learners' lives and concerns.

D. The novelty element: aspects of an activity that is new or different or totally unexpected.

E. The intriguing element: tasks that concern ambiguous, problematic, paradoxical, controversial, contradictory or incongruous material stimulate curiosity.

F. The individual choice: tasks which give learners a personal choice. For example learners can choose their own topics to write about in an essay or choose their own topics and group members in a discussion activity.

G.The tasks that encourage risk taking: Tasks that encourage learners not to be so worried about making mistakes when they take part in activities. Reward is for effort and not only for success.

H.The tasks that encourage original thought: Activities that require an original response. Instead of comprehension questions after a reading passage that test recall, they seek to use tasks that encourage a personal and individual response to what the learner has read.

I. The fantasy element: Activities that engage the learners' fantasy and that invite the learners to use their imagination for creating make-believe stories, identifying with fictional characters or acting out imaginary situations.

The researcher sums up below eight simple activities with their linguistic purpose as guidelines to promote creative language production:

1: Using grammar and structures:

In the following activity, learners remember grammar and test their memory skills.

Student A: $I$

Student B: I went

Student C: I went to

Student D: I went to the museum

Student E: I went to the museum and I

Student F: I went to the museum and I saw

Student G: I went to the museum and I saw many
Student H: I went to the museum and I saw many ancient things.

\section{2: Creating a fictional story}

In the following activity, learners sit in a semicircle. Each learner says a complete sentence. Learners try to make the emerging story as coherent as possible.

Student A: George went to school.

Student B: George went to school and he had a bike accident.

Student C: It was very serious; his leg was bleeding (new word).

Student D: He called his mother.

Student E: His mother fainted (new word).

The learners can use a dictionary and to be assisted by the teacher or help one another.

\section{3: Promoting creative writing:}

Learners are divided into two groups. Both groups sit in a semicircle and are given a sheet of paper that says: "Yesterday I had a bad dream." Then, learners in both groups have to write a story and then hand it to their partners to continue writing about the same subject and complete the story. The group who has the best story with the best grammar and content would get points.

This activity not only promotes teamwork and peer editing, but also gives learners liberty of expression, interest, and purpose in the course of work.

4: Introducing vocabulary through screenwriting:

According to Argentini (1998: 98), screenwriting is a document that outlines every aural, visual, behavioral, and lingual element required to tell a story. The way learners visualize the story they want to write, based on their experience or their imagination, is relevant in the process of acquiring smoothness in writing. With this form of creative writing, Al-Alami (2013: 98) suggests that learners start with the creation of an idea; then the learner fleshes out that idea into actions, dialogue, characters, and scenes. With screenwriting, learners visualize a story, and they can turn a simple sentence or idea into a properly formatted screenplay.

\section{5: Sharing a speech:}

In this strategy, learners can use whatever they want to say. They can choose interesting speeches such as personal information about their lives, family, love, life problems, favourite movie, their best or worst experience, and so forth. With this activity, teachers get the chance not only to see learners' limited language, but they know what the learners like. The 
way learners give and share their speech will be influenced by experiences from the past, expectations for the future and will contribute to teachers' practices (Kelchtermans, 2009: 257).

\section{6: Drawing circles of life:}

Learners draw big circles. In these circles, they write about the most significant aspect of their lives. For example in Circle 1, they write the most meaningful number for them; in Circle 2, the object they could not live without; in Circle 3, the most important name for them. Learners then stand up and walk around the classroom sharing every circle with the other students. For instance, Learner A shares with his classmates that (2) is his most significant number because he has two brothers. This technique is effective because students interact with one another, listen to what the other says. A friendship could be formed this way and they practise their oral skills as well.

\section{7: Drawing and speaking:}

In order to practise speaking, learners draw something they want to share on the board and explain why it is drawn. After that, another learner comes up and draws another object or person next to it. After all the participants draw their objects, they will have to create a story based on the drawings on the board. Learners have the opportunity to share their stories with others and evaluate their own process with peer feedback. They have the challenge to create a story with those drawings which may be funny. Besides, they will know more about their classmates' personalities.

\section{8: Asking and answering questions:}

Learners write as many questions as they can about anything they want. They should be careful about grammar and the structures for asking a question. After that, each one of them comes up front and sits in a chair while the other classmates ask them the questions they write. This exercise is beneficial because learners can learn the structures of questions in the English language. The class becomes active since all learners participate and they ask each one of their peers interesting questions which enable them to be more prepared for interviews in the future.

The researcher would like to share what Robert Fisher says:

"What promotes creativity is a questioning technique by which teachers and learners ask unusual questions, represent ideas in different ways; physically and verbally, and critically evaluate new ideas and actions."

It is worth taking into consideration here Chomsky's (1976:133) opinion when he says that "creativity is predicted on a system of rules and forms, in part determined by intrinsic human capacities. Without such constraints, we have arbitrary and random behaviour, not creative acts."

\section{Section Three}

\section{How English Textbooks Stimulate Critical Thinking}

When we define critical thinking as an intellectually disciplined process of actively and skillfully conceptualizing, applying, analyzing, synthesizing, and/or evaluating information, we hereby refer to Bloom's taxonomy when he considers these skills as higher-order thinking skills. Critical thinking is specifically that "level of reading comprehension or discussion skills when the learner is able to question and evaluate what is read or heard. In language teaching this is said to engage students more actively with materials in the target language, encourage a deeper processing of it, and show respect for students as independent thinkers." (Richards and Schmidt, 2002: 135). Critical thinking is thus to be contrasted with the mere acquisition and retention of information because it involves a particular way in which information is treated and used.

The question here is how to stimulate language learners' critical thinking. Textbook designers try to introduce a wide range of thinking activities, but what are the types of such activities? The choice of the thinking activities depends on the objectives of teaching and the learners' age. The following list includes categories of activities that range from the lowest level to the highest level as identified by Mirman and Tishman (1988: 64):

- Lower level activities: drawing and coloring, copying, reading aloud, silent reading and watching, memorizing, revising, simple comprehension, looking things up, etc.

- Higher level activities: imaginative writing tasks, collecting evidence, problem solving, deducing, reasoning tasks, application tasks, analysis tasks, synthesis tasks, evaluation, creation, summarizing, etc.

Pedagogically speaking, the basic assumption of the communicative approach to language teaching emphasizes the use of language as a communication tool and hypothesizes that learners become proficient by using the language and not just by 
learning about the language. It is therefore logically to believe that learners can only become proficient language users if they, besides using the language and knowing the meaning, can display creative and critical thinking through the language. This implies that the learners must be creative in their production of ideas, and critically support them with logical explanation, details and examples. Nevertheless, creative and critical thinking skills should not be taught separately as an isolated entity, but embedded in the subject matter and woven into the curriculum. For this purpose and for the aim of this research, textbooks designers should seek to develop the learners' cognitive abilities to carry out certain tasks effectively. They must be able to carefully and deliberately determine to accept or reject judgment about something. Lipman (1988: 38) adds that critical language learners must also be able to identify and cite good reasons for their opinions and answers, correct themselves and others' methods and procedures, and adapt to uniformities, regularities, irregular circumstances, special limitations, constraints and over-generalizations. We can propose that critical thinking pedagogy requires posing questions to learners and listening to learners' questions. This is a practice which forces and challenges the learners to think creatively and critically, and to adopt a critical attitude towards the world. Thus, it is extremely vital that teachers should be informed how to ask questions in different ways in order to enhance the cognitive development of learners. Costa and Marzano (1987: 33) demonstrated this by using specific terminology, posing critical questions and creating new labels to structure perceptions such as:

Instead of saying: "Let's look at these two pictures." Say: "Let's compare the two pictures."

On the other hand, teachers' beliefs and attitudes about themselves, and their functions in language classrooms have momentous implications for learners' ability to think creatively and critically. If the teachers think that their primary roles are to teach and provide answers and information, then the learners are exposed to the culture of "spoonfeeding". Eventually, the learners" ability to look for answers and solutions, and to inquire, to decide, to question, to reject and to accept ideas will greatly diminish. Teachers need to believe that their major roles are to think, guide, initiate, facilitate and encourage the learners. What is important here is to follow a certain methodology of posing critical questions.
For that purpose, textbooks can make learners experience the problem-posing through five steps of methodology (Nixon-Ponder, 1995:3):

1. Describe the content of discussion

2. Define the problem

3. Personalize the problem

4. Discuss the problem

5. Discuss the alternatives of the problem

Besides, decision making processes could also be used to sow the seeds of critical thinking into language learners. First of all, the topics identify common and real situations or problems to be discussed by the learners. Then the three steps of decision-making strategies are used (Mirman and Tishman, 1988: 62):

1. Find creative options to the situations or problems

2. List reasons for and against the most promising options, and

3. Make a careful choice out of list of reasons

The learners, who act as the judges, analyze the evidence provided, rationalize the reasons, and weigh their judgments. These kinds of activities provide chances for learners to voice their opinions, thoughts, beliefs and views, and to strengthen their critical thinking in relations to the real problems that are so often found in the real world.

Among the factors affecting language learners' critical thinking skills is the assessment methods used when these methods seek to measure whether critical thinking improves English writing ability, language proficiency and oral communication ability. Before all, the objectives of the textbooks, as Brown (2004: 25) asserts, should go beyond linguistic factors in order to develop critical thinking among learners rather than, as Davidson (1998: 121) says, to help them to go from one educational level to the next. In fact, in many cases the way of assessment is determinant of the objectives of the language learning program. If in a language teaching context, assessment focuses on linguistic competence of the learners, mastery of linguistic competence becomes the learners' objective, while in a context emphasizing communicative competence, learners do their best to become communicatively competent in the foreign language. In the same way, if the focus of assessment is on integrating language and thinking skills, the learners do their best to achieve this objective. Alderson and Wall (1993:115) state that "tests are held to be powerful determiners of what happens in the classroom." Test 
effects are described in terms of "participants" such as teachers, students, administrators, materials writers, and publishers, "process" referring to those actions taken by participants to complete teaching and learning tasks and "product" referring to learning outcomes and the quality of learning. Hughes' model implies that the quality of a test determines to a high degree the level and amount of backwash (Pan, 2009: 74).

Below are some suggestions that are identified by the researcher for reinforcing critical thinking through assessment procedures:

1. Use ongoing assessment as "a systematic approach to collecting information and making inferences about the ability of a student on the basis of various sources of evidence" (Richards and Schmidt, 2002: 35), rather than one-shot exams at the end of the semester. While one-shot exams require the test taker to have a limited amount of knowledge, mostly linguistic, ongoing assessment carried out during the course gives the teacher the opportunity to test a larger range of knowledge and skills, including critical thinking skills.

2. Use criterion-referenced (CR) testing rather than norm-referenced (NR) testing. In NR testing, "a test taker's score is interpreted with reference to the scores of other test takers" (ibid: 363). It encourages learners to attempt to be better than others without thinking about what they learn and how they use it. In CR testing, "the test taker's score is interpreted with reference to a criterion score" (ibid: 133). It welcomes the differences among learners and consequently differences among learners lead to learners' learning from each other in a friendly noncompetitive atmosphere. While the learners become more cooperatives than competitors, they become more concerned with understanding than with outcomes. As such they help each other in developing critical thinking skills.

3. Use activities in your assessment which encourage the learner to think critically. Those activities which can be carried out through simpler processes such as memorizing, substituting, etc. are not appropriate activities for enhancing critical thinking in language learners. Better activities for the purpose of promoting critical thinking skills are those which require the learners to think, cooperate and ask questions.

4.Provide learners with feedback which gives learners understanding not only of how well they have carried out the activities but also how they might improve them. Feedback must come from a variety of perspectives: from students' reflection on their own work, from classmates reflecting on one another's work, and from the teacher. The ultimate goal here is to develop the learners' critical thinking.

\section{Section Four}

\section{How English Textbooks Provide Collaborative Learning Activities}

Collaborative learning appears when learners work together to reach a shared goal. It is occasionally used as a synonym for cooperative learning; however, they follow slightly different principles. For example, Matthews, Cooper, Davidson and Hawkes (1995:36) illustrate the differences between collaborative and cooperative learning in terms of the role of the teacher, the involvement of students, and the relationship between the teacher and the learners. They clarify that in comparison with cooperative learning, collaborative learning is less organized by the teacher, as the learners are given more responsibility of their own learning and evaluation. "In collaborative learning, teachers teach students collaborative or social skills so that they can work together more effectively." (LarsenFreeman,2000: 164)

Theodore Panitz suggests that the former is more of a philosophical approach rather than merely a pedagogical one where mutual respect and responsibility between group members are built on cooperative efforts. Oxford (1997: 446) similarly infers that collaborative learning is based on building functional learning communities that focus more on the learner's adjustment to the community than on concrete learning procedures. Collaborative learning, however, can then be, as Oxford concludes, associated with social constructivism, which focuses on the whole learning process as opposed to single tasks to be completed. Dillenbourgh's (1999:9) definition of collaborative learning is among the most specific ones, as he mentions four features that can serve as the criteria of evaluation when determining the meaning of the word 'collaborative'. $\mathrm{He}$ states that situations, interactions, and learning mechanisms as well as the effects of collaborative learning should all be considered when using the term, and emphasizes that in a collaborative context the parties involved, who are equal in status, must work together towards a shared objective via collaborative procedures. Dillenbourgh (1999: 11) also differentiates between collaborative and 
cooperative learning by explaining that collaboration requires group members working together whereas in cooperation the workload is divided between the group members.

As for educational approaches, Smith and MacGregor (1992: 11) view collaborative learning as follows:

"Collaborative learning" is an umbrella term for a variety of educational approaches involving joint intellectual effort by students, or students and teachers together. In most collaborative learning situations students are working in groups of two or more, mutually searching for understanding, solutions, or meanings, or creating a product.

In order for a group of activities to be considered successfully collaborative, it must fulfill certain criteria. Johnson and Johnson (1999:75-88) list five fundamental elements that educators should consider when applying collaborative approaches: positive interdependence, individual accountability, face-toface interaction, interpersonal and small group skills, and group processing.

1.Positive interdependence requires all participants to complete their share of the workload. All group members have been assigned a specific role in the group with relation to their personal abilities, thus the group cannot function without all of its members' participation, as everyone's input is equally important.

2. Individual accountability emphasizes that all members of the group should afterwards be able to perform a similar task on their own. It should therefore be ensured that everyone in the group gains new knowledge and skills from the collaborative activity in order for them to have the capacity to do the same on their own later.

3. Face- to-face interaction is needed to accomplish concrete tasks as well as for mutual support.

4. Interpersonal and small group skills involve not only working on different tasks, but initially working together in a group.

5. Finally, group processing is a way to evaluate the group's success in order to see which procedures were helpful and which ones need improvement.

It is on these five elements that English activity books should be evaluated. Whenever examining an English language textbook, one should be aware of not only the characteristics of the approach, but also its effects and benefits. The learners are naturally the ones who benefit from collaborative learning the most. Crandall (1999:233-234) presents an overview of the reasons to use collaborative learning in the context of language learning. For example, collaboration in the language classroom is believed to lower learners' anxiety level; therefore, learners are likely to be more actively involved in class activities, as increased opportunities to plan and practise their answers and language with the group prior to performing to the whole class. Moreover, Crandall points out that collaboration in the language classroom requires learners to adjust their speech according to the other group members' requests of clarification which results in producing more coherent language use that is easier for everyone involved to understand.

To reinforce the scope of this research, it has been found that collaborative learning can also improve learners' critical thinking. Crandall (1999:234-235) concludes the discussion on the benefits for learners by noting how peer support has a positive effect on learners' self-confidence and self-esteem as well as their motivation in a way that collaboration and mutual encouragement creates a safe, supporting atmosphere for students to participate in class, which furthermore leads to a higher motivation level to do so. As for the learning environment, collaborative learning is likely to increase the quantity and quality of learner performance, create a favourable climate for intercultural communication, and promote learner-centered classroom procedures and learner autonomy (ibid: 235-240).

Laal and Ghodsi (2012: 487-488) approach this matter from a different perspective as they recite the benefits of collaborative learning collected from various sources in four main categories. The first category is called social benefits, and it refers to the effects collaboration has on the learning community such as increased cultural appreciation and better climate for learning. The second category holds the psychological benefits of collaborative learning, and besides the effective factors on learners' self-esteem and anxiety discussed in the paragraph above, it also includes the increase in positive learner attitudes towards teachers. The third category by the name of academic benefits emphasizes the improvement of learning outcomes, and the fourth category calls attention to diversity of evaluation methods that collaboration provides for both teachers and learners.

\section{Conclusion}

The researcher sums up the major features of language learning textbooks that can develop learners' communication skills, creative language production, critical thinking and collaborative 
learning when they perform and demonstrate what they learn as follows:

1. Meaningful practice activities in which learners make meaningful choices when carrying out those activities are the best for developing learners' communication skills.

2. The contents of a language textbook should be based on social communicative functions and not merely on linguistic structures.

3. Creative tasks in t he language textbooks lead to genuine communication and co-operation. They prepare learners for using the language instrumentally outside the classroom.

4.Imaginative writing tasks, collecting evidence, problem solving, deducing, reasoning tasks, application tasks, analysis tasks, synthesis tasks, evaluation, creation and summarizing promote critical thinking.

5. Group work leads to collaborative work and has a positive effect on learners' self-confidence and self-esteem.

\section{$\underline{\text { References }}$}

1. Al-Alami, S. (2013) Utilizing Fiction to Promote English Language Acquisition. Newcastle, UK: Cambridge Scholars Publishing. In Hernán A. Avila, Creativity in the English Class: Activities to Promote EFL Learning: 98 https://howjournalcolombia.org/index.php/ho w/article/view/141

2. Alderson, C., \& Wall, D., "Does Wash-back Exist?" Journal of Applied Linguistics: 14, pp. 115-129, 1993.

3. Argentini, P. (1998) Elements of Style for Screenwriters: The Essential Manual for Writers of Screenplays. Boulder, CO. Lone Eagle Press. In Hernán A. Avila, Creativity in the English Class: Activities to Promote EFL Learning: 98 https://howjournalcolombia.org/index.php/ho w/article/view/141

4. Brown, H.D., "Some Practical Thoughts about

5. Students- Sensitive Critical Pedagogy, Journal of The

6. Language Teacher, 28 (7), pp. 23-27, 2004.

7. Byram, Michael, Assessing Intercultural Communicative Skills. Uk: Multilingual Matters Ltd. 1997.

8. Chomsky, Noam, "On Nature and Language", Cambridge University Press, Cambridge 1976, In V.J. Cook and M. Newson (2007)
Chomsky's Universal Grammar: An Introduction ( $3^{\text {rd }}$ edition). USA: Blackwell Publishing. pp. 17-8, 1976.

9. Costa, A.L. \& Marzano, R., "Teaching the Language of Thinking," Journal of Educational Leadership, 45(2), pp. 29-33, 1987.

10. Crandall, J. (1999) Cooperative Language Learning and Affective Factors. In Affect in language learning, J. Arnold(ed.), Cambridge University Press, Cambridge, pp. 226-245, 1999.

11. Csikszentmihalyi, M., Creativity: The Psychology of Discovery and Invention., NY: Harper Perennial, New York, 2013.

12. Davidson, B, "A Case for Critical Thinking in the English Language Classroom," Journal of TESOL Quarterly, 32, pp. 119-123, 1998.

13. Dillenbourg, P., Collaborative Learning: Cognitive and Computational Approaches, Elsevier, Amsterdam, 1999.

14. Hymes, D. H., "On Communicative Competence," In Sociolinguistics: Selected Readings, J. B. Pride, \& A. Holmes (eds.), Penguin, Harmondsworth, 1972.

15. Johnson, D. W. and Johnson, R. T., "Learning Together

16. and Alone: Cooperative, Competitive and Individualistic Learning, ( $5^{\text {th }}$ ed.), Allyn and Bacon, Boston, 1999.

17. Kelchtermans, G., "Who I am in how I teach is the message: Self- understanding, vulnerability, and reflection." Journal of Teachers and Teaching: Theory and Practice, 15 (2), pp. 257-272, 2009.http://dx.doi.org/10.1080/13540600902 875332.

18. Kramsch, Claire, Language and Culture, Oxford University Press, Oxford, 2001.

19. Laal, M. and Ghodsi, S. M., "Benefits of Collaborative Learning," Journal of Procedia-Social and Behavioral Sciences 31 (0), pp. 486-490, 2012.

20. Larsen-Freeman, Diane, Techniques and Principles in Language Teaching $\left(2^{\text {nd }}\right.$ ed.), Oxford University Press, UK, 2000.

21. Lipman, M., "Critical Thinking: What It Can Be?" Journal of Educational Leadership, 46 (1), pp. 38-43, 1988.

22. Matthews R. S., Cooper J. L., Davidson N. and Hawkes P. "Building bridges between cooperative and collaborative learning," 
Journal of Change, pp. 34-40. July/August, 1995.

23. Mirman, J. and Tishman, S. "Infusing thinking through connections," Journal of Educational Leadership, 45(7), pp. 64-65, 1988.

24. Naiman, L., "Fostering Innovation in an IT World" Canadian Information Processing Society Journal. In Hernán A. Avila, Creativity in the English Class: Activities to Promote EFL Learning: pp. 93, 1998. https://howjournalcolombia.org/index.php/ho w/article/view/141

25. Nixon-Ponder, Sarah, "Using Problemposing Dialogue in Adult Literacy Education. Teacher to Teacher, In Journal of ERIC: 381677. Washington: Department of Education, 1995.

26. Oxford, R. L., "Cooperative learning, collaborative learning, and interaction: Three communicative strands in the language classroom," The Modern Language Journal 81(4), Special Issue: Interaction, Collaboration and Cooperation: Learning Languages and Preparing Language Teachers, pp. 443-456, 1997.

27. Pan, Y., "Do Tests Always Work?", The International Journal of Educational and Psychological Assessment, 2, pp. 74-88, 2009.

28. Panitz, T., Collaborative versus Cooperative Learning - A Comparison of the two Concepts which will help us Understand the Underlying Nature of Interactive Learning, 1996.

Available:

home.capecod.net/ tpanitz/tedsarticles/coop definition.htm [Accessed:10 Nov., 2017).

29. Razmloo, S., "High Schools or Private Institutions Textbooks? Which Fulfill Communicative Language Teaching Principles in Iranian Context?" Asian EFL Journal: The EFL Professional's Written Forum, 9, 4, pp. 126-140, 2007.

30. Richards, Jack C., Creativity in Language Teaching, University of Hong Kong, Hong Kong, 2013.

31. Richards, J., Communicative Language Teaching Today, Cambridge University Press, Cambridge, 2005.

32. Richards, Jack C. and R. Schmidt, Longman Dictionary of Language Teaching and Applied Linguistics, ( $3^{\text {rd }}$ ed.), Pearson Education Ltd., UK, 2002.
33. Savignon, S. "Communicative Language Teaching for the Twenty First Century" In Teaching English as a Second/Foreign Language, M. Murcia (ed.), p. 12-28, MA: Heinle \& Heinle, Boston, 2001.

34. Smith, B. L. and MacGregor, J. T., "What is Collaborative Learning?" In Collaborative Learning: A Sourcebook for Higher Education. A. S. Goodsell, M. R. Maher, and V. Tinto (eds.),University Park, PA: National Center on Postsecondary Teaching, Learning, and Assessment, pp. 10-29, 1992.

35. Yalden, J., Communicative Syllabus: Evolution, Design and Implementation, Pergamon Press, New York, 1982 